\title{
Simulation of the medical syringe injection moulding process
}

\author{
Sebastian Białasz ${ }^{1, *}$, and Tomasz Klepka ${ }^{1}$ \\ ${ }^{1}$ Lublin University of Technology, Mechanical Engineering Faculty, Nadbystrzycka 38, 20-618 Lublin, Poland
}

\begin{abstract}
This paper contains a description of tests including the simulation of the injection moulding of thin-walled products. The simulation was designed to analyse the potential impact of processing conditions and cooling conditions on the defects of thin-walled products of the body of the syringe. In order to obtain the correct results, the analysis was based on a simulation comparison with the data obtained after the injection mouldings were produced. Four cases were considered - parameters with reduced injection pressure and absence of pressure push, with a reduced temperature of the injection mould. The test results were analysed in conditions compliant with the recommendations of the production card and with the parameters optimised by computational algorithms of the computer programme. Simulations were carried out using the Simcon CadMould 3D-F programme. The paper describes the construction of a thin-walled body, which is the main segment of a medical instrument - a medical syringe. Also described in the paper are the process of injection of polymer materials and the characteristics of the production of medical syringes. In addition the computer programme software for the simulation of production processes was presented.
\end{abstract}

\section{Introduction}

The injection of fluids into the human body is possible with the use of a dispensing medical instrument colloquially called a syringe. The product consists of a thin-walled body in the form of a cylindrical container and a highly resistant profile functioning as a piston [2]. Because both elements can be made of polymer materials, the obtained product will typically satisfy technical requirements and ensuring low manufacturing costs, bioneutrality and sterility. Products of this type are obtained in a cyclic injection process, which is the most widely used method for polymer plastics processing $[6,8]$.

Production costs of an average syringe are low, as nowadays, multi-mass and mass production are widespread. Therefore, engineers must plan the technological process and select the appropriate parameters so as to minimise unnecessary capital expenditures, which include the purchase costs of the device, tools, and material. High costs of maintaining the high-sterility work environment in which medical accessories and instruments are produced also need to be taken into consideration. Therefore, it is important to carry out preliminary tests and comparative analyses regarding the technological process procedures and the properties of the products in order to minimise all costs and rational selection of process conditions $[2,6,8]$.

This type of technical-economic analysis is possible using computer-aided modelling and simulation of the polymer processing process. The aim of the paper is to simulate the injection of a thin-walled element in the form of a syringe body and show how the choice of processing conditions can affect the quality of manufactured products in the real process of plastics processing.

\section{Specification of medical syringes}

The syringe is a sterile medical accessory made up of a cylindrical graduated container and a piston. This product is mainly used to draw blood or inject drugs into the human body of a certain volume. For a dozen or so years, the use of traditional, glass and metal, reusable syringes has been abandoned, in favour of disposable plastic syringes. The main reason for this change is the difference in production costs and good utility features. In the case of traditional syringes, the cost of maintenance, sterilisation and repair, calculated per treatment, is greater than the price of a disposable needle and syringe in a sterile package, ready for use. Products made of plastics are also better in technical terms because the body of plastic syringes, among other things, does not break (in contrast to glass), is tighter and also more resistant to aging [12].

Currently, syringes are used in medicine for injection or withdrawal of extracorporeal fluids. There are also insulin and tuberculin syringes, and infusion pumps. A large number of accessories, i.e. various needles or cannulas, are used along with syringes. An example of the syringe is shown in Figure 1.

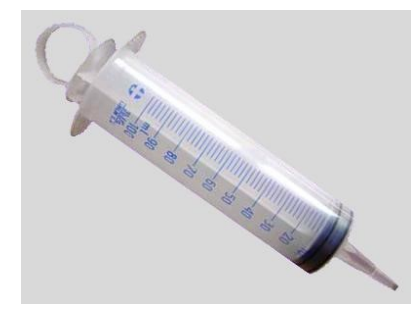

Fig. 1. An exemplary polypropylene syringe.

* Corresponding author: sebastian.bialasz@pollub.edu.pl 
The plastics used for forming the syringe body must meet certain basic conditions. First of all, the material must be safe to use considering its biological properties, so that no toxic or chemical substances inert to the drugs are used for injection. It must also exhibit adequate mechanical properties - sufficient bending resistance, tensile strength, impact strength, shape durability, as well as specific transparency and adequate aging resistance. Currently, sterile bodies for injection syringes are mainly made of polypropylene. However, it is also worth mentioning that oral syringes are made of low-impact, transparent polystyrene, whose pure, monomer-free polymer is biocompatible and not toxic to the human body. Due to the fact that they must exhibit high tensile and compression strength, medical syringe pistons are most often produced from high-density polyethylene (HDPE) $[2,6]$.

Thin-walled syringe bodies and pistons are manufactured in the extrusion process. In order to obtain a low product unit cost and to minimise production costs, multi-cavity moulds are used for this type of products. An exemplary multi-cavity mould is shown in Figure 2.

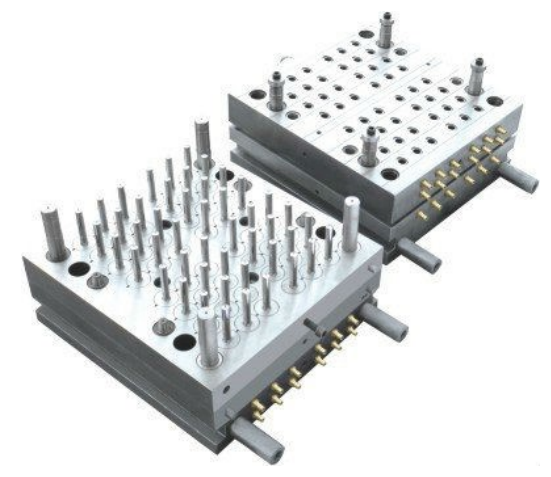

Fig. 2. Injection mould for producing thin-walled syringe bodies.

\section{Numerical simulation in the processing of polymeric materials}

Nowadays, the entire manufacturing process is more and more integrated with computer-aided solutions - CAE (Computer-Aided Engineering). Such methods enable elimination of errors that would occur at later stages of production, already at the design level of a given product or process. One of the functions of computer-aided production is the possibility of computer simulations. The most popular software for simulating the injection process is: MOLDFLOW, CADMOULD, MOLDEX3D and VISI-Flow.

Due to the fact that most of the defects of the mouldings are the result of construction errors of the injection mould in connection with the product's geometry, it is reasonable to use numerical simulations at the design stage. The use of injection moulding simulation offers a multitude of benefits, some of are presented in Table 1.
Table 1. Benefits of using numerical simulation.

\begin{tabular}{|c|c|}
\hline ECONOMY & QUALITY \\
\hline $\begin{array}{c}\text { reduction of prototyping } \\
\text { costs and preparation of the } \\
\text { so-called first injection }\end{array}$ & $\begin{array}{c}\text { obtaining information about } \\
\text { phenomena occurring } \\
\text { during solidification of the } \\
\text { compact inside the socket }\end{array}$ \\
\hline $\begin{array}{c}\text { reduction of time from the } \\
\text { first steps related to the } \\
\text { construction of the model to } \\
\text { the first moulding or } \\
\text { extrudate }\end{array}$ & $\begin{array}{c}\text { determining the kinetics of } \\
\text { nest filling (pressure } \\
\text { gradient, temperature })\end{array}$ \\
\hline $\begin{array}{c}\text { material savings } \\
\text { optimisation of the injection } \\
\text { process - shorter cycle time } \\
\text { reducing the number of } \\
\text { critical places in the volume } \\
\text { of mouldings }\end{array}$ & $\begin{array}{c}\text { marking the level of stress } \\
\text { arising inside the nest } \\
\text { from the point of view of } \\
\text { filling the nest }\end{array}$ \\
$\begin{array}{c}\text { indication of air traps } \\
\text { together with the markings } \\
\text { of the line connecting the } \\
\text { streams of the material with } \\
\text { the temperature given } \\
\text { during the connection }\end{array}$ \\
\hline precise cost estimation & $\begin{array}{c}\text { determination of the } \\
\text { contraction distribution and } \\
\text { deformation of the compact }\end{array}$ \\
\hline reducing the costs of tool \\
design & $\begin{array}{c}\text { estimation of the level of } \\
\text { tangential stresses arising } \\
\text { during the nest filling }\end{array}$ \\
\hline & \\
\hline
\end{tabular}

\section{Programme and research object}

The testing programme encompasses the implementation of numerical simulation of the injection process and the execution of physical moulds in order to verify the correctness of the obtained results from the numerical simulation. Four different cases of changing the processing conditions were considered:

- case 1 - basic parameters;

- case 2 - reduced injection pressure no pressure of pressure;

- case 3 - reduced temperature of the injection mould;

- case 4 - optimal parameters suggested by the computer programme;

The CadMould 3D-F programme was used to simulate the injection moulding process. The $3 \mathrm{D}$ model of the syringe was made in the SolidEdge ST7 programme. The file was converted to *.stl format and then imported by CadMould. The numerical model is a representation of the body of a $100 \mathrm{ml}$ syringe (Figure 3 ).

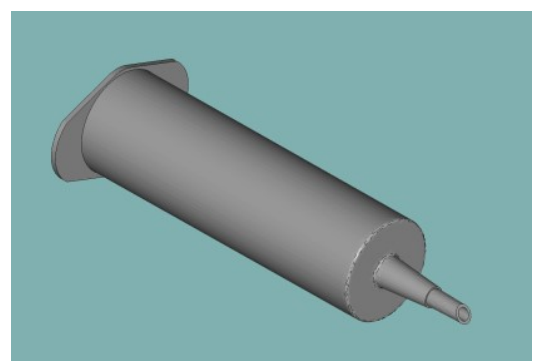

Fig. 3. The design of the syringe filter: a) upper cover, b) lower cover. 
The syringe, which served as the test pattern, was made of PPM Total H250 (modified polypropylene). Since such material is not available in the CadMould programme, material with similar properties and an identical mass flow index of the polymeric material of 25 $\mathrm{g} / 10 \mathrm{~min}$ was selected. This material bears the name PPH 9081 (it is also modified polypropylene). The table below contains basic material information.

Table 2. Technical data sheet Polypropylene PPH 9081.

\begin{tabular}{|l|c|c|c|}
\hline & Method & Unit & Value \\
\hline Rheological properties & & & \\
\hline $\begin{array}{l}\text { Melt Flow Index } \\
230^{\circ} \mathrm{C} / 2.16 \mathrm{~kg}\end{array}$ & ISO 1133 & $\begin{array}{c}\mathrm{g} / 10 \\
\text { min }\end{array}$ & 25 \\
\hline Thermal properties & \multicolumn{3}{|l|}{} \\
\hline Melting Point & ISO 3146 & ${ }^{\circ} \mathrm{C}$ & 165 \\
\hline Vicat Softening Point & ISO 306 & ${ }^{\circ} \mathrm{C}$ & \\
\hline 50N-50 ${ }^{\circ} \mathrm{C}$ per hour & & & 80 \\
\hline Heat Deflection Temp. & \multirow{2}{*}{ ISO 752} & ${ }^{\circ} \mathrm{C}$ & \\
\cline { 1 - 2 } $1.80 \mathrm{MPa}-120^{\circ} \mathrm{C}$ per $\mathrm{h}$. & & & 52 \\
\hline Other physical prop. & \multicolumn{3}{|l}{} \\
\hline Density & ISO 1183 & $\mathrm{~g} / \mathrm{cm}^{3}$ & 0.905 \\
\hline Bulk Density & ISO 1183 & $\mathrm{~g} / \mathrm{cm}^{3}$ & 0.525 \\
\hline
\end{tabular}

To carry out the simulation, the input parameters listed in Table 3 were used.

Table 3. Input parameters of the considered cases.

\begin{tabular}{|l|c|c|c|c|}
\hline considered cases & $\mathbf{1}$ & $\mathbf{2}$ & $\mathbf{3}$ & $\mathbf{4}$ \\
\hline mould temperature $\left[{ }^{\circ} \mathrm{C}\right.$ & 36 & 36 & 22 & 30 \\
\hline injection pressure [bar] & 110 & 45 & 110 & 110 \\
\hline $\begin{array}{l}\text { resultant injection time } \\
{[\mathrm{s}]}\end{array}$ & 1,1 & 1,1 & 1,1 & 1,1 \\
\hline pressure 1 [bar] & 100 & - & 100 & 100 \\
\hline pressing time 1 [s] & 2 & - & 2 & 2.55 \\
\hline clamping pressure 2 [bar] & 90 & - & 90 & - \\
\hline time pressure 2 [s] & 0,4 & - & 0,4 & - \\
\hline cooling time [s] & 9 & 9 & 9 & 7,28 \\
\hline
\end{tabular}

The last part of the research was the production of the physical bodies of syringes, using injection technology. The syringes were obtained using a two-socket mould.

\section{Research and tests}

The first stage of preparation for extrusion simulation was the execution and uploading of the syringe CAD model. After uploading the 3D CAD model, it was necessary to perform approximation with the triangles of the surface of the solid.

The software enables setting the density of the MES grid based on which it will perform calculations related to the simulation (Figure 4).

In the CadMould programme, it is also possible to design (simplified) filling channels with neckings. For the purpose of simulation, an infusion channel was designed, which was a single inlet module located in the tangible injection mould (Figure 5).

In order to perform the simulation, the developed model was meshed and the infusion canals were designed along with the overpasses. Next, the polymeric material on which the analyses were carried out was selected. Then the injection parameters were set for four cases (according to the test program).

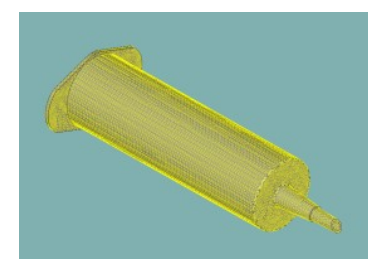

Fig. 4. 3D model of the syringe with the MES mesh applied.

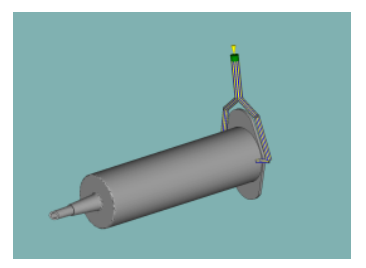

Fig. 5. 3D model with infusion canals.
Thje numerical simulation of the injection process equipped us with information about the phenomena occurring during the injection process, as well as the behaviour of the moulding upon removal from the forming cavity. The following phenomena were analysed: - plastic flow path

- problems with filling the form

- contribution of supply canals

- gradient of injection shrinkage

- temperature distribution in the compact

- possible surface deformation (collapse)

- drop in the material flow pressure in the cavity.

\section{Results and discussion}

\subsection{Output data in the simulation process}

In the process of numerical simulation relevant data on parameters and processing properties was produced; the data is presented in Table 4.

Table 4. Output data for numerical injection simulation.

\begin{tabular}{|l|l|l|l|l|}
\hline cases considered & $\mathbf{1}$ & $\mathbf{2}$ & $\mathbf{3}$ & $\mathbf{4}$ \\
\hline $\begin{array}{l}\text { minimum } \\
\left.\text { temperature [ }{ }^{\circ} \mathrm{C}\right]\end{array}$ & 218.3 & 218.3 & 218.3 & 215.4 \\
\hline $\begin{array}{l}\text { maximum } \\
\left.\text { temperature [ }{ }^{\circ} \mathrm{C}\right]\end{array}$ & 235.7 & 235.7 & 235.7 & 235.7 \\
\hline $\begin{array}{l}\text { ]maximum } \\
\text { pressure [bar] }\end{array}$ & 530.6 & 472.4 & 553.9 & 628.1 \\
\hline $\begin{array}{l}\text { deformation } \\
\text { assessment [\%] }\end{array}$ & 0.3 & 0.3 & 20.1 & 0.3 \\
\hline $\begin{array}{l}\text { maximum shear } \\
\text { rate during the } \\
\text { filling phase [1 / s] }\end{array}$ & 43978 & 43978 & 43978 & 40269 \\
\hline $\begin{array}{l}\text { max. temperature } \\
\text { during the filling } \\
\text { phase [ }{ }^{\circ} \mathrm{C} \text { ] }\end{array}$ & 245.5 & 245.5 & 245.5 & 245.1 \\
\hline $\begin{array}{l}\text { required cooling } \\
\text { time [s] }\end{array}$ & 12.658 & 10.524 & 11.501 & 10.524 \\
\hline
\end{tabular}

\subsection{Flow of the material in the socket}

Based on the simulation, a breadth of information about the course of the injection process (e.g. the flow of the plastic), as well as the behaviour of the mould after removal from the cast (e.g. collapse, contractions) were obtained.

The first considered phenomenon was the flow path of the material, the contribution of inlet canals and problems with filling the nest. For all four cases, these phenomena 
proceeded without problems, which indicates the lack of influence of the set parameters on these properties. It also proves a proper construction of the product structure.

The simulation results are shown in Figure 6.

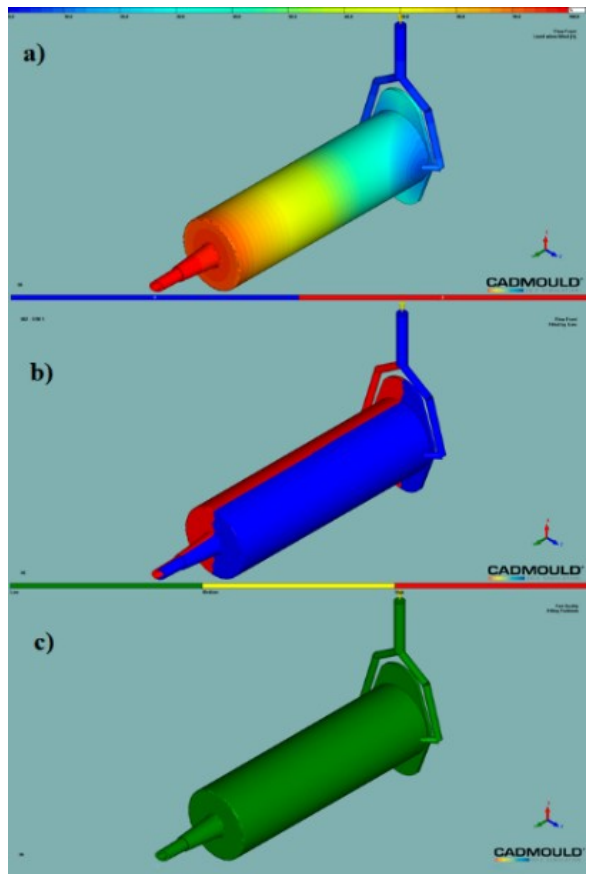

Fig. 6. Simulation of socket infusion: a) flow path of material, b) contribution of supply canals, c) problems with socket filling.

\subsection{Gradient of injection shrinkage}

One of the phenomena that could be observed using numerical simulation is the gradient of injection shrinkage. Injection contraction affects the change of the dimensions and shape of the moulding. In the case of the injected body of the syringe, it grew mostly in places where there was a change (turning points) of the flow path of the material (bends, wall corners, etc.). Large shrinkage volume occurred also in the place where the material was flowing from the infusion channels into the syringe mould. It can be inferred that this phenomenon may be desirable at this point, in order to easily separate the finished products from the supply canals. The phenomenon of injection shrinkage is illustrated in Figure 7. a)

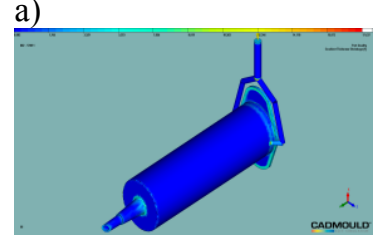

c)

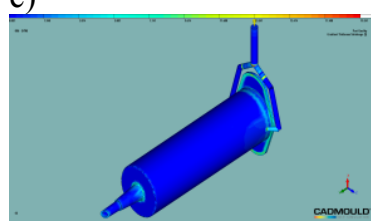

b)

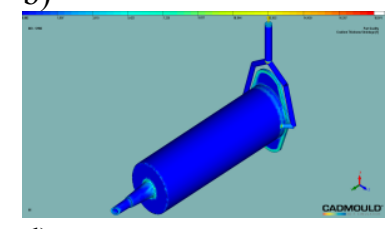

d)

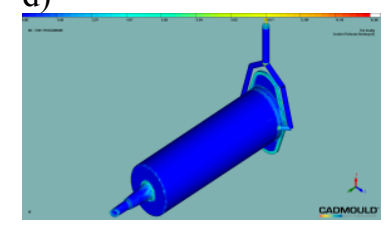

Fig. 7. Gradient of injection shrinkage a) case 1, b) case 2, c) case $3, \mathrm{~d}$ ) case 4 .
In addition, the simulation enabled generating a plot of the injection contraction value alongside the supporting wall of the body (Fig. 8).

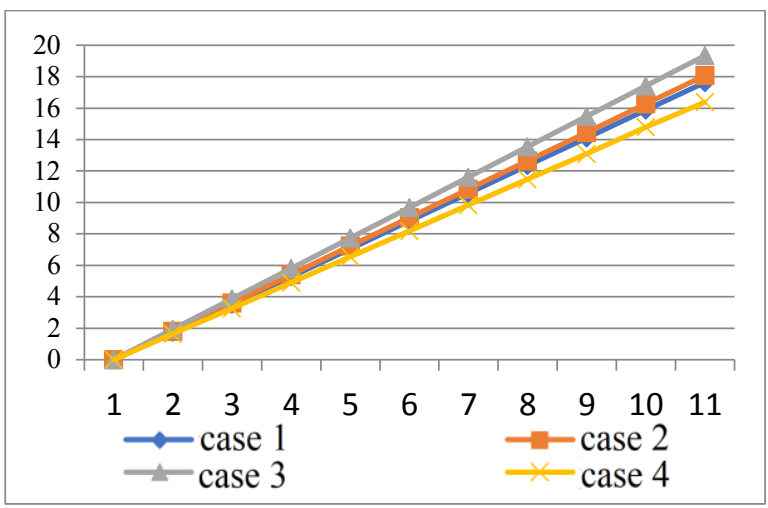

Fig. 8. Scatter plot of injection shrinkage values for all cases.

The value of injection shrinkage was similar for all four cases, which indicates that the parameters adopted have only a slight influence on this phenomenon.

\subsection{Pressure drop in the socket}

With CadMould, it was possible to generate graphs presenting fluctuations in pressure values increasing over time during filling the socket (Fig. 9). a)

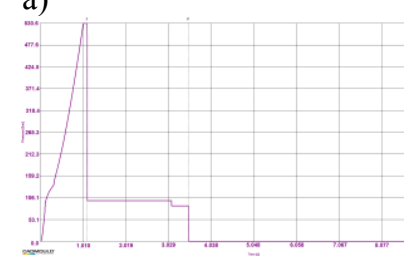

c)

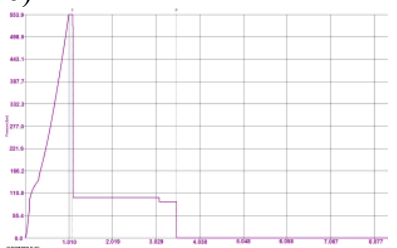

b)

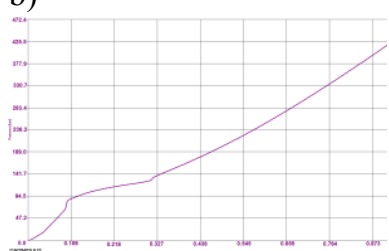

d)

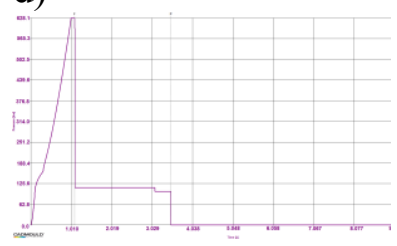

Fig. 9. Graph of the change in the pressure value from the injection time for the cases: a) 1, b) 2, c) 3, d) 4 .

These graphs show respectively the increase in pressure during the flow of the material through the mould, a sudden drop and the pressure stabilisation during the clamp and the lack of pressure in the final stages of the process. In the second case, probably due to the target lack of the clamp pressure, the pressure on the graph was recorded until the cast was filled. Graphs of the dependence of injection pressure on time are shown in Figure 9.

The pressure drop in the socket has the value reciprocal to the pressure of the plastic stream and the highest values occur at the end of the cast - in a place where the most frequent deformations occur. This phenomenon is shown in Figure 10. 


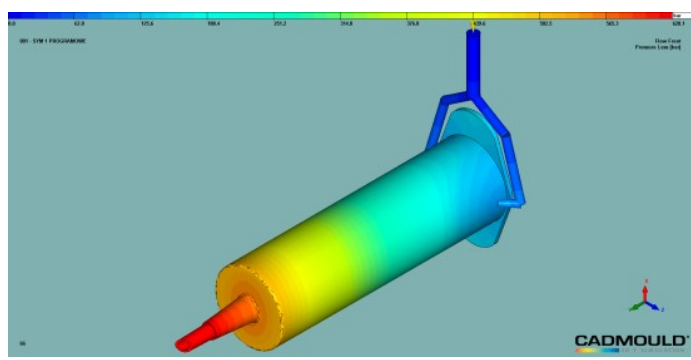

Fig. 10. Pressure drop for case 4.

In order to compare this phenomenon for all 4 cases, all results were collected and presented on a common chart. The graph below (Figure 11) shows the dependence of the pressure drop on the degree of filling the cast along its length for all cases.

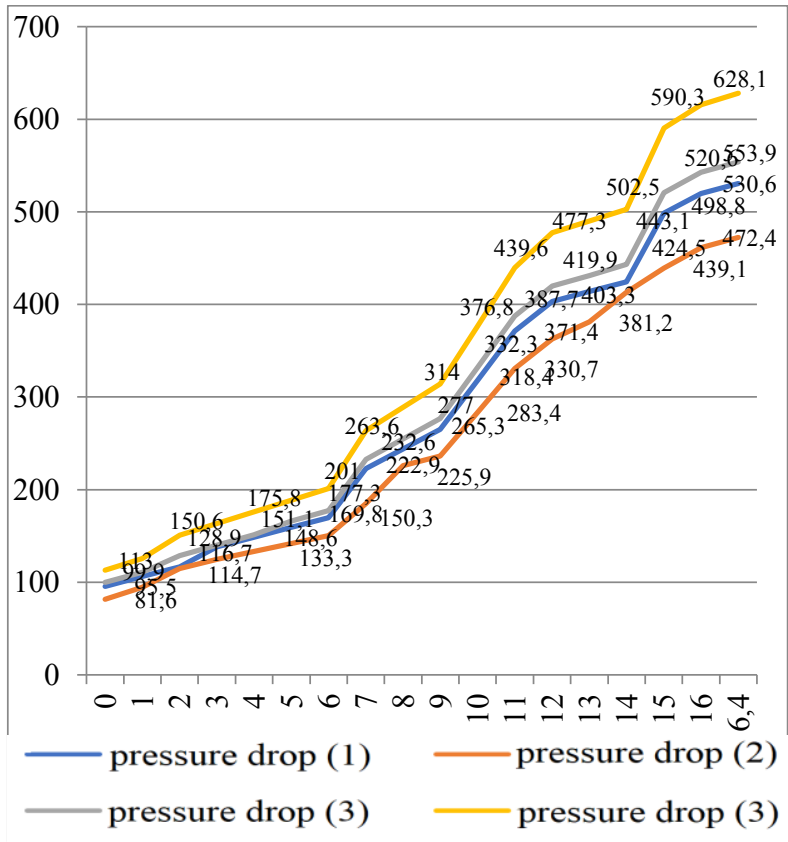

Fig. 11. Comparative graph of pressure drop along the injection cast.

Excessive pressure drop can cause stagnation of the plastic stream in the socket or inaccurate filling of the socket.

\subsection{Temperature distribution during injection}

The next data that can be obtained from the numerical simulation is the temperature distribution during filling the injection mould cavity. Figure 12 shows an example of the visualisation of the temperature distribution in the final stage of filling the socket with the material.

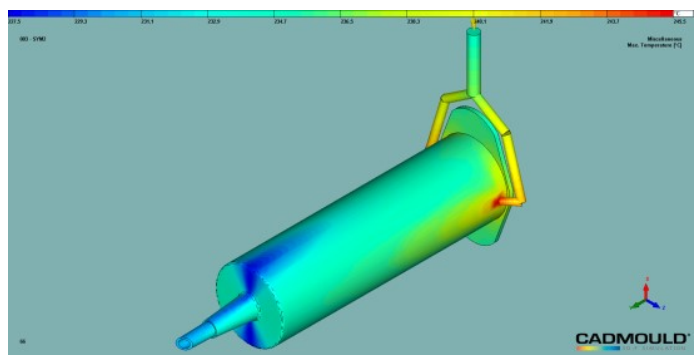

Fig. 12. Distribution of temperatures in case 3 .
In Figure 12, the dark-blue spaces are the places where the temperature is the lowest (its value can be read from Table 1). The highest temperature is marked in red. For all 4 examined cases, the temperature distribution was similar and correct, i.e. there was no zone of congestion (a consequence of insufficient temperature of material) or overheating of the polymeric material.

\subsection{Distortion of the surface - collapse}

The next value that can be read from the results of the simulation is the value of the collapse (deformation) of the surface of the moulding. In the case of casts representing the first and fourth cases, potential deformations are small and most often caused by a sudden change in the direction of flow of the material through the cast. The second case also does not differ significantly from those above. In the third case, the largest deformation of the surface was observed. The results of this simulation are shown in Figure 13.

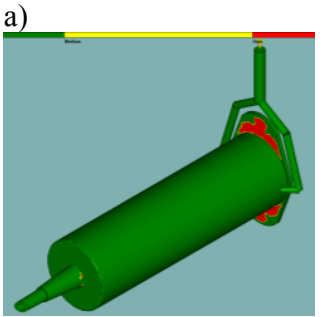

c)

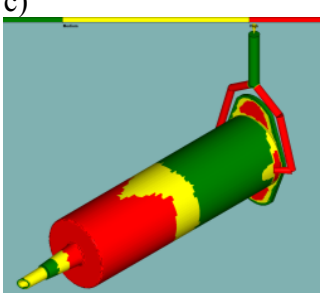

b)

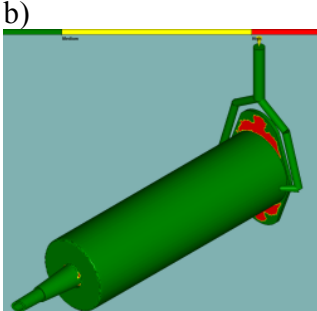

d)

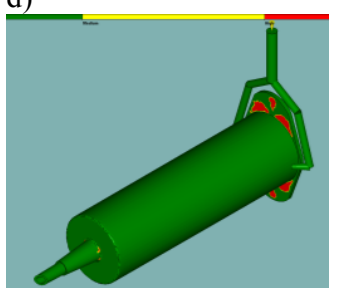

Fig. 13. Possible distortions of the surface: a) case 1, b) case 2, c) case 3, d) case 4 .

\subsection{Selection of injection models}

After analysing the results of the simulation, the third case was chosen based on which the physical product was made. Due to the high similarity of the results, case 4 was excluded from further studies (high resemblance to the first case). The injection process was then carried out using parameters concurrent with numerical simulations. Figure 14 shows the appearance of the resulting casts at various process parameters.
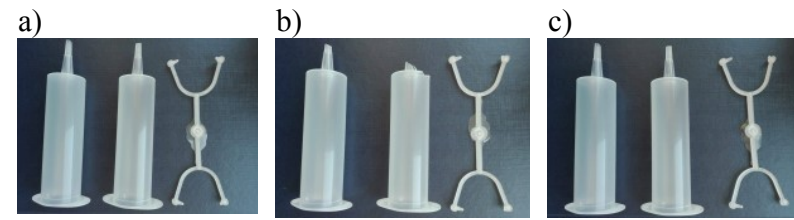

Fig. 14. Compacts obtained by injection, using the parameters of subsequent cases: a) one, b) two, c) three.

As shown in Figure 14, the use of parameters with the second case brought the worst effect. The first case is a properly manufactured syringe. In the second, the injection pressure was lowered and the clamp phase was 
omitted. In this case, we see the greatest surface deformation that was not accounted for in the simulation. The third case is the reduced temperature of the form. This mould has a correct shape, however, it has much thinner walls at the end of the syringe in comparison to the model. These places coincide with the simulation result, but the deformations are not as large as predicted by the simulation.

Moreover, it was shown that the parameters generated by the programme and the parameters from the technical sheet of the material are similar and the differences in values are not substantial. It can be, therefore, assumed that the CadMould programme performs well. The algorithm that selects the injection parameters does not include the possibility of a two-stage pressure, so that simulation results will not actually reflect the physical conditions.

As shown in the simulation, the areas most exposed to deformation are those where the material had to rapidly change its flow direction through the injection mould. These places are more likely to have an injection spatter. The largest pressure drops are at the end of the syringe, and since the shear force is also higher there - the highest probability of deformation occurs there. Experimentally, this is best seen in the example of the reduced temperature of the injection mould, where the risk of distorting the syringe is the greatest.

\section{Summary and conclusions}

Based on the conducted study in the CadMould programme, it can be concluded that performing simulations only approximates the physical conditions and is a help in well-adjusted injection parameters. The results obtained are correct, but they only approximate the possible result and do not fully reflect the real problems. The implemented software offers limited possibilities in the range of matching input values: certain defined parameters are omitted. Sometimes, if the entered value drifted away too far from the norm, the programme interrupted the simulation and recommended changing the given parameter to a more suitable, hence the simulation of the injection with incorrect parameters could not be carried out in accordance with the assumptions. The programme allows you to run simulations for a single mould while in the industrial environment the mass scale is quite more common. Moreover, a simplified model of infusion canals can affect the obtained test results. The point at which the material begins to flow, is defined in the programme as a mathematical point, thus it can be assumed that the flowing material has no beginning, and the earlier stages of the plastification process are not taken into account.

Computer simulation is an interesting and useful tool for engineers, but requires knowledge regarding how to operate it, how to read the measurement results and how they apply to real conditions in order to obtain the best results when designing new products.

\section{References}

1. J.P. Beaumont, R. Nagel, R. Sherman: Successful Injection Molding: Process, Design, and Simulation. (Hanser Gardner Publications, Cincinnati, 2002)

2. G. Durek, T. Pawela, J. Wnukiewicz, Dent. Med. Probl. 45, 85-88 (2008)

3. T. Garbacz, J. Sikora, Przetwórstwo tworzyw polimerowych, ćwiczenia laboratoryjne, czesść 1 . (Wydawnictwo Politechniki Lubelskiej, Lublin, 2012)

4. B. Grabowska, AFE, 10/2, $57-60$ (2010)

5. C.A. Harper, Handbook of Plastic Processes. (Wiley Interscience Publishers, 2006)

6. T. Jachowicz, T. Garbacz, A. Tor-Świątek, I. Gajdoš, A. Czulak, JPAC 20, 307-315 (2015)

7. D.O. Kazmer, Injection Mold Design Engineering. (Hanser Publications, 2007)

8. T. Klepka, R. Jeziórska, A. Szadkowska, Przem. Chem. 94, 1352-1355 (2015)

9. D. Kwiatkowski, J. Nabiałek, Kompozyty, 4, 93-95 (2005)

10. J. Pielichowski, A. Pruszyński, Technologia tworzyw sztucznych. (WNT, Warszawa, 1998)

11. K. Wilczynski, Polymers, 44, 6 (1999)

12. Patent Application no. PL 169177 (1992) 